\title{
Penerapan Aplikasi Pendukung Touring Pada Komunitas Motor Berbasis Android
}

\author{
M. Khairul Anam ${ }^{1}$, Reksi Anwar ${ }^{2}$ \\ ${ }^{1,2}$ Program Studi Teknik Informatika, STMIK Amik Riau \\ email:khairulanam@sar.ac.id ${ }^{1}$, reksianwarr@gmail.com ${ }^{2}$
}

(Received: 11 Maret 2020/ Accepted: 17 April 2020 / Published Online: 20 Juni 2020)

\begin{abstract}
Abstrak
Google maps merupakan aplikasi pemandu jalan untuk sampai ke tujuan, namun fitur pada google tidak ada fasilitas touring. Touring sering dilakukan oleh komunitas sepeda motor ataupun mobil, touring biasanya diikuti lebih dari satu kendaraan. Dalam melakukan touring tidak jarang ada anggota yang tertinggal yang tidak diketahui oleh pemimpin touring atau Road Captain. Kejadian seperti ini sering kali menjadi keterlambatan sampai ke tujuan dikarenakan road captain terlambat mengetahui anggotanya yang tertinggal. Tujuan dari penelitian ini adalah membangun aplikasi touring, aplikasi tersebut memiliki fitur notifikasi. Notifikasi didapat ketika anggota yang menjauh dari Road Captain dengan radius yang sudah di perhitungkan. Riders yang tetinggal dapat diketahui lebih awal keberadaanya sehingga touring bisa dilanjutkan dengan lancar. Aplikasi ini telah diuji cobakan kepada salah satu komunitas motor dipekanbaru. Pada uji coba yang telah dilakukan, bahwa aplikasi ini sangat membantu perjalanan touring yang dilakukan oleh komunitas tersebut. Aplikasi touring ini dapat diinstal pada sistem Operasi Android Lollipop atau 5 ke atas. Jadi, dapat disimpulkan bahwa penggunaan aplikasi touring ini dapat digunakan dan layak untuk digunakan dalam melakukan touring keberbagai daerah oleh komunitas motor atau mobil.
\end{abstract}

Kata Kunci: Android, Global Positioning System (GPS), Komunitas Motor, Touring

\begin{abstract}
Google map is a road guide application to facilitate people getting some alternative routes to get a certain location, unfortunately. Google has no features to support touring facilities. Touring usually carried out by motor or car communities, and followed by more than one vehicle. While touring sometimes the members left behind or lost without knowing by the Road Captain. This is one of the obstacles to get the destination on time, because of the road captain is late knowing the members who lost and left behind. The purpose of this research is to create a touring application, which has a notification feature. The notification will light up when a member moves away from the Road Captain with a certain calculation radius. Members who lost can identify quickly so that the touring activities can run smoothly. This application has been tested by one of the motorcycle communities in Pekanbaru. After carried out a trial, it proved that this application is very helpful for their touring trips. This application can run on Android operating system 5 and above. Therefore, it can be concluded that this touring application can be used, and it is feasible for traveling trips to various regions by motorcycle or car community.
\end{abstract}

Keywords: Android, Global Positioning System (GPS), Motorcycle Community, Touring.

\section{PENDAHULUAN}

Pengguna kendaraan bermotor seperti mobil dan motor saat ini telah banyak mendirikan komunitas. Komunitas merupakan suatu kelompok yang terdiri dari berbagai macam individu, berkumpul menjadi satu atas suatu kesamaan (Nurbanaat \& Desiningrum, 2018). Namun komunitas motor ini dipandang sebagai suatu geng yang meresahkan warga diberbagai daerah di Indonesia. Hal ini dapat dilihat dari berita pada televisi ataupun media online seperti portal berita (detik.com, liputan6.com, dan lain sebagainya) atau offline seperti 
Koran dan majalah. Penelitian terkait dengan kekerasan geng motor sudah dilakukan beberapa peneliti sebelumnya (Khaerul, Julianto, \& Salmah, 2017; Sunarsa, 2018). Peneliti lain juga melakukan penelitian terkait dengan komunitas motor, berbeda dengan kedua peneliti. Peneliti mendapatkan temuan bahwa komunitas kendaraan bermotor sering melakukan pertemuan, pertemuan ini ada bersifat hiburan, edukatif, dan social (Gama \& Gama, 2015). Dalam melakukan pertemuan biasanya para anggota melakukan touring keberbagai daerah. Komunitas biasanya menggunakan smartphone sebagai pentunjuk arah dengan menggunakan aplikasi Global Positioning System (GPS). GPS merupakan sistem navigasi dengan menggunakan teknologi satelit yang dapat menerima sinyal dari satelit (Alfeno \& Devi, 2017). Saat ini pengguna smartphone di Indonesia sebesar 64,8\% dari total populasi penduduk pada tahun 2018 (APJII, 2019). Smartphone di Indonesia yang paling banyak digunakan adalah android. Gambar 1 merupakan penjualan smarphone di Indonesia pada tahun 2019 (Canalys, 2019).

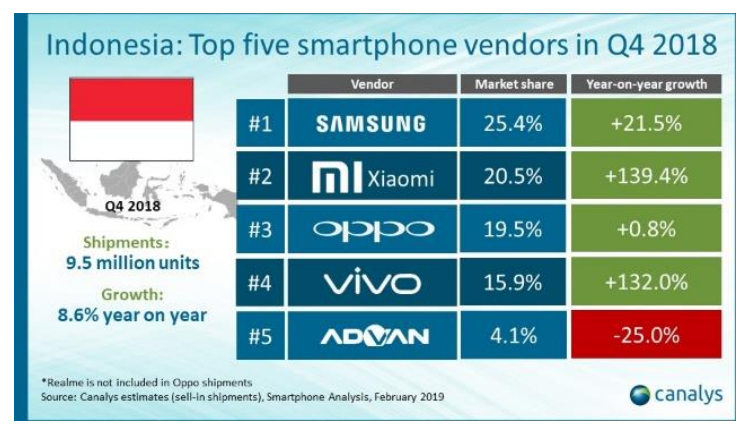

Sumber : (Canalys, 2019)

Gambar 1. Penjualan Smartphone di Indonesia

Komunitas motor dalam melakukan aktivitas touring mereka selalu berinteraksi dengan alat komunikasi seperti handphone (Wahanahonda, 2018). Menurut bikers disalah satu komunitas motor yang ada di Pekanbaru saat ini smartphone sangat penting untuk dibawa saat touring selain barang yang penting lainnya. Permasalahan yang terjadi dilapangan adalah ketika menggunakan smartphone tidak adanya aplikasi untuk touring. Dalam mempermudah perjalanan mereka menggunakan aplikasi aplikasi Google Maps. Namun, penggunaan aplikasi Google Maps, tidak menyediakan fitur yang bisa menunjukkan pada saat anggota tertinggal ataupun salah jalan, sehingga tidak dapat terdeteksi oleh aplikasi ini. Dengan demikian, pemimpin jalan atau Road Captain yang didepan tidak mengetahui akan hal itu dan menyebabkan keterlambatan sampai tujuan pada komunitas ini.

Penelitian sebelumnya telah membahas perancangan aplikasi pendukung touring berbasis contextual awareness (Rahardi, Nugroho, \& Ferdiana, 2016). Penelitian menghitung jarak antar anggota peserta touring menggunakan metode K-Nearest Neighbour. Hasil yang diperoleh perancangan ini mampu memahami pengguna, jaringan, lingkungan dan mampu beradaptasi dengan dinamis sesuai kebutuhan.

Penelitian yang dilakukan adalah untuk mengatasi permasalahan yang sering menjadi kendala dalam melakukan touring. Tujuannya adalah untuk mengetahui keberadaan anggota yang tertinggal denga cara mengirimkan pesan atau notifikasi kepada anggota, agar anggota mendapatkan notifikasi dan informasi secara cepat dan akurat ketika melakukan touring serta meningkatkan keamanan dalam berkendara.

\section{METODE}

Untuk mempermudah dalam melakukan penelitian perlu adanya sebuah alur metodologi. Gambar 2 merupakan alur metodologi yang digunakan pada penelitian ini. 
Metodologi ini merupakan adopsi dari metode waterfall. Metode Waterfall adalah suatu proses pengembangan perangkat lunak berurutan, di mana kemajuan dipandang sebagai terus mengalir ke bawah (seperti air terjun) melewati fase-fase perencanaan, pemodelan, implementasi (konstruksi), dan pengujian (Tristianto, 2018).

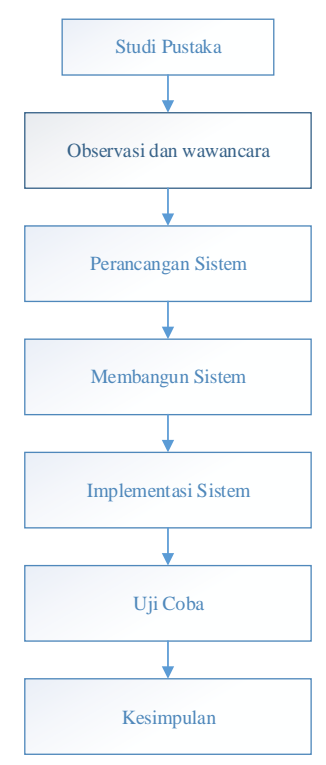

Gambar 2. Alur Metodologi

Berikut ini merupakan penjelasan dari Gambar 2.

\section{Studi Pustaka}

Pada tahapan ini, mencari penelitian-penelitian terdahulu terkait dengan penelitian yang akan dilakukan.

\section{Observasi dan Wawancara}

Observasi dan wawancara terhadap salah satu komunitas motor yang ada di Kota pekanbaru yaitu Komunitas Motor "HOBIKU". Wawancara dilakukan terhadap ketua dan 5 orang anggota komunitas tersebut. Hal ini dilakukan untuk mengetahui apa saja yang menjadi kendala ketika komunitas tersebut mengadakan touring.

\section{Perancangan Sistem}

Setelah diketahui permasalahan yang didapat, langkah selanjutnya ialah melakukan perancangan system. Perancangan yang dilakukan meliputi system yang akan dibangun dan perancangan perangkat lunak.

\section{a. Sistem yang akan dibangun}

Gambaran yang diusulkan adalah pada sisi aplikasi, ketua dapat melakukan pengolahan data baik berupa pembuatan event baru atau melihat anggota yang terdaftar. Anggota juga dapat melihat informasi detail dari kegiatan touring yang akan dilakukan. Pada aplikasi ini, sistem akan melakukan pengiriman data lalu datanya akan dikonversi kedalam bentuk JSON sebelum data dikirim ke server dan disimpan dalam database. Untuk mendapatkan data dari database data yang di request oleh aplikasi akan dikonversi dahulu ke dalam JSON lalu dikonversi ke dalam bentuk data yang bisa dibaca oleh android.

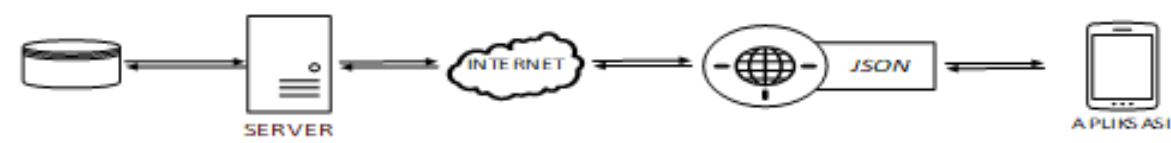

Gambar 3. Rancangan sistem aplikasi yang diusulkan 


\section{b. Perancangan perangkat lunak}

\section{Unified Modeling Language}

Unified Modeling Language atau biasa disingkat dengan UML merupakan sebuah bahasa yang berdasarkan grafik atau gambar untuk memvisualisasi, menspesifikasikan, membangun, dan pendokumentasian dari sebuah sistem pengembangan software berbasis OO (Object-Oriented)(Suendri, 2018). Ada beberapa tools pada UML, salah satunya adalah usecase. usecase menjelaskan secara visual konteks dari interaksi antara aktor dengan system (T. A. Kurniawan, 2018). Berikut ini adalah usecase pada system yang diusulkan

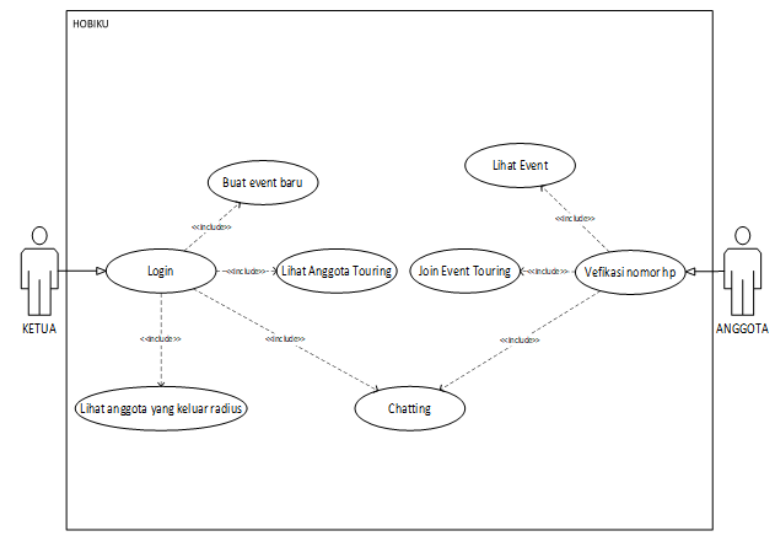

Gambar 4. Usecase

\section{Rancangan antarmuka Aplikasi}

Berikut ini adalah beberapa tampilan antar muka dari sistem aplikasi touring.

\section{Event Touring}
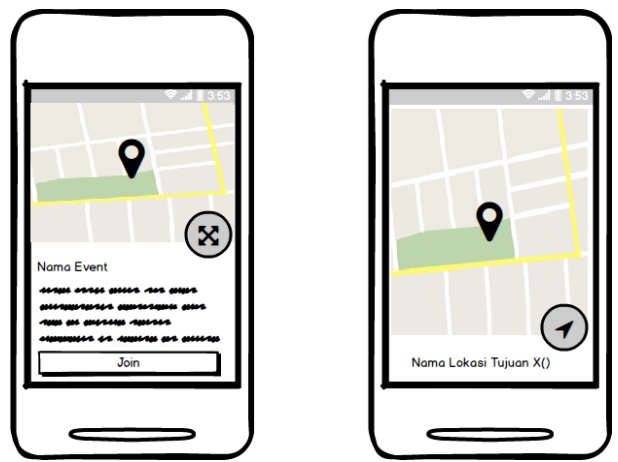

Gambar 5. Event Touring

Gambar 5 menunjukan bahwa halaman ini merupakan halaman konfirmasi anggota yang ingin bergabung atau join event yang akan berlangsung.

\section{Halaman Peta}

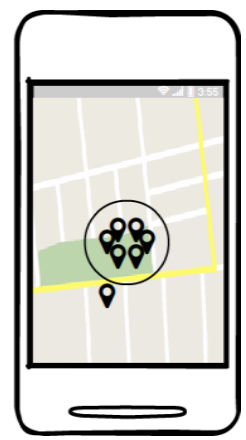

Gambar 6. Halaman Peta 
Gambar 6 merupakan halaman peta yang berfungsi untuk menampilkan semua anggota yang sedang melaksanakan event yang berlangsung.

\section{Anggota keluar dari rombongan}

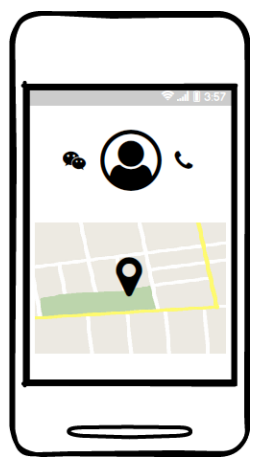

Gambar 7. Anggota Keluar dari Rombongan

Gambar 7 merupakan halaman untuk menampilkan detail anggota yang telah keluar dari rombongan, pada halaman ini ketua dapat menghubungi anggota yang tersesat secara langsung atau mengirimkan pesan pribadi kepada anggota melalui whatsapp.

\section{Membangun Sistem}

Pada tahap ini membangun sistem berdasarkan rancangan yang telah dibuat sebelumnya yaitu rancangan antarmuka aplikasi.

\section{Implementasi dan uji coba Sistem aplikasi}

Setiap anggota touring wajib untuk melakukan instalasi system aplikasi pada smartphone android mereka. Setelah itu dilakukan uji coba untuk memastikan bahwa system aplikasi yang dibut berjalan dengan lancer.

\section{Blackbox}

Black Box Testing berfokus pada spesifikasi fungsional dari perangkat lunak. Tester dapat mendefinisikan kumpulan kondisi input dan melakukan pengetesan pada spesifikasi fungsional program (Mustaqbal, Firdaus, \& Rahmadi, 2015).

\section{HASIL DAN PEMBAHASAN}

Hasil

Hasil yang diperoleh pada penelitian ini adalah sebuah sistem aplikasi touring yang telah diuji cobakan kepada salah satu komunitas HOBIKU di pekanbaru. Dalam melakukan uji coba, para anggota komunitas HOBIKU mengisi pertanyaan terkait dengan sistem aplikasi touring. Selain itu sistem aplikasi ini juga di uji cobakan kebeberapa versi android yang digunakan untuk mengetahui sistem ini berjalan atau tidak ketika versi android berbeda.

Pembuatan aplikasi ini menggunakan tools seperti android studio, Sublime Text 3, dan Xampp. Untuk itu aplikasi yang telah siap dijalankan selanjutnya dilakukan build APK. Android Application Package File (APK) adalah paket aplikasi Android (Android Package). APK umumnya digunakan untuk menyimpan sebuah aplikasi atau program yang akan dijalankan pada perangkat Android (Hafsah, Rustamadji, \& Sriyono, 2012).

Aplikasi yang sudah diinstal pada smartphone, selanjutnya ialah melakukan pendaftaran menjadi anggota ataupun ketua. Gambar 8 merupakan tampilan untuk mendaftar menjadi anggota. 


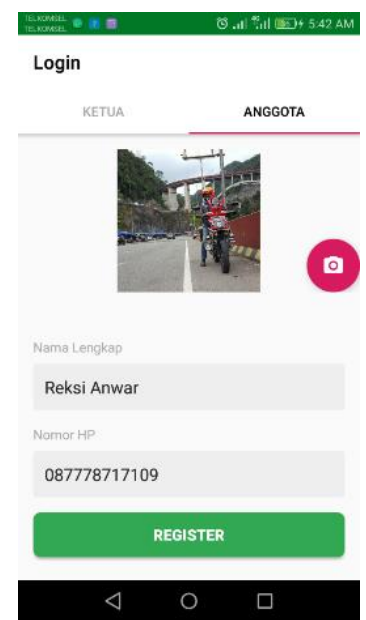

Gambar 8. Proses Pendaftaran

Riders yang sudah melakukan pendaftaran anggota akan mendapat kode OTP seperti pada Gambar 9. OTP singkatan dari One Time Password untuk verifikasi sementara dan hanya bisa diakses oleh penggunanya itu sendiri sehingga bisa mengurangi potensi penyadapan hak akses (Naufal \& Purwanto, 2018). Setiap riders yang sudah bisa masuk kedalam aplikasi, riders tersebut bisa melakukan join event touring seperti pada Gambar 10. Event touring pada aplikasi ini berguna untuk riders yang ingin bergabung dengan anggota lainnya untuk melakukan touring ke suatu tempat. Bagi riders yang sudah bergabung, mereka bisa melakukan chatting terkait dengan persiapan touring ataupun pada saat perjalanan saat touring nantinya. Hal ini terlihat pada Gambar 11.

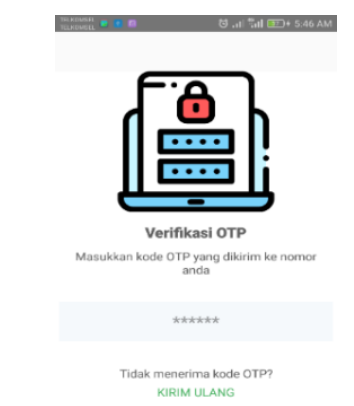

Gambar 9. Kode OTP

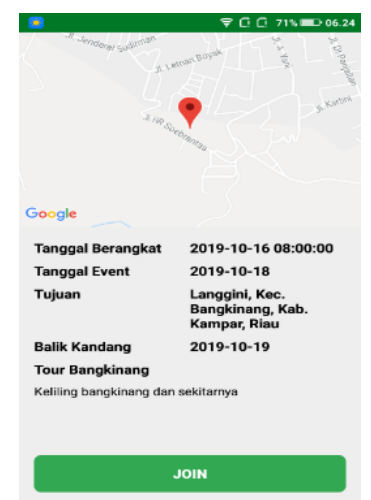

Gambar 10. Join Event Touring 

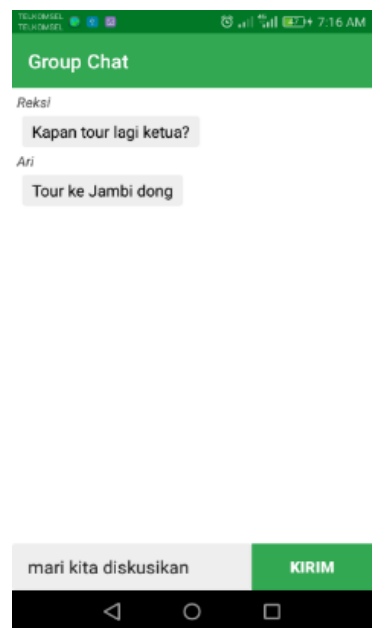

\section{Gambar 11. Fitur Chatting}

Ketika melakukan perjalanan pada aplikasi android, terlihat berapa orang yang mengikuti touring ini. Gambar 12 merupakan kegiatan saat touring yang terlihat pada aplikasi. Gambar 13 menunjukan ketika ada anggota touring yang tersesat, ketua anggota akan mendapatkan notifikasi dari sistem, dan ketua touring bisa mengetahui dan langsung menghubungi anggota yang tertinggal atau tersesat.

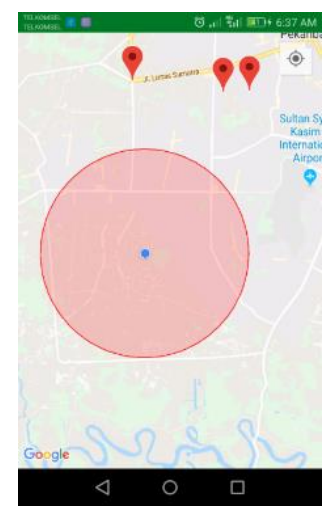

Gambar 12. Lokasi Anggota Touring

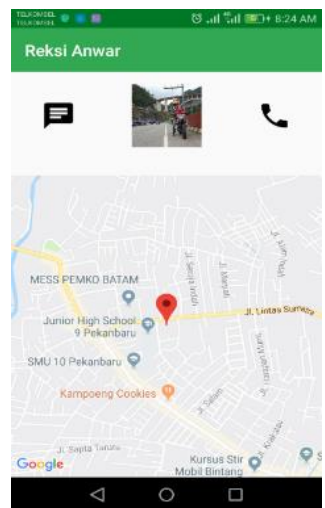

Gambar 13. Detail Anggota

Langkah-langkah di atas merupakan pengujian untuk uji coba aplikasi touring. Setelah melakukan uji coba selanjutnya ialah Pengujian Black Box. Berdasakan skenario pengujian yang disusun, maka dilakukan pengujian, untuk penjelasan lebih lanjut tentang pengujian data benar aplikasi program dapat dilihat pada tabel dibawah ini. Pengujian ini melibatkan 
komunitas HOBIKU untuk melakukan uji coba pada aplikasi yang telah diterapkan untuk melakukan touring.

1. Kasus dan hasil pengujian

Berikut ini merupakan hasil coba dari sistem aplikasi yang telah diterapkan.

Tabel 1. Hasil Pengujian

\section{Kasus dan Hasil Uji (Data Benar)}

\begin{tabular}{|c|c|c|c|}
\hline Data & Skenario & Hasil yang diharapkan & Kesimpulan \\
\hline $\begin{array}{l}\text { Fitur menu } \\
\text { utama }\end{array}$ & $\begin{array}{c}\text { Menampilkan Daftar } \\
\text { Event, }\end{array}$ & $\begin{array}{l}\text { Dapat berjalan } \\
\text { menampilkan menu utama }\end{array}$ & $\begin{array}{c}{[\sqrt{ }] \text { Berhasil }} \\
{[-] \text { Tidak berhasil }}\end{array}$ \\
\hline $\begin{array}{l}\text { Fitur maps } \\
\text { atau lokasi }\end{array}$ & $\begin{array}{l}\text { Menampilkan lokasi } \\
\text { marker tujuan lokasi }\end{array}$ & $\begin{array}{c}\text { Dapat berjalan } \\
\text { Menampilkan lokasi tujuan }\end{array}$ & $\begin{array}{l}{[\sqrt{ }] \text { Berhasil }} \\
{[-] \text { Tidak berhasil }}\end{array}$ \\
\hline Detail & $\begin{array}{l}\text { Menampilkan detail } \\
\text { event }\end{array}$ & $\begin{array}{l}\text { Dapat menampilkan } \\
\text { informasi detail event }\end{array}$ & $\begin{array}{c}{[\sqrt{ }] \text { Berhasil }} \\
{[-] \text { Tidak berhasil }}\end{array}$ \\
\hline Notifikasi & $\begin{array}{c}\text { Menampilkan } \\
\text { notifikasi kepada } \\
\text { ketua jika ada anggota } \\
\text { keluar dari radius }\end{array}$ & $\begin{array}{l}\text { Dapat menampilkan } \\
\text { notifikasi }\end{array}$ & $\begin{array}{c}{[\sqrt{ }] \text { Berhasil }} \\
{[-] \text { Tidak berhasil }}\end{array}$ \\
\hline
\end{tabular}

Tabel 1 menunjukan hasil pengujian diatas dapat ditarik kesimpulan bahwa fitur-fitur dalam aplikasi yang dibangun dapat berjalan dengan lancar untuk menjalankan fungsi dari aplikasi tersebut.

2. Pengujian pada versi android

Penelitian pengujian dilakukan terhadap jenis atau versi android yang digunakan untuk mendapatkan hasil apakah di semua jenis android aplikasi ini dapat berjalan dengan baik sesuai dengan hasil yang di harapkan.

Tabel 2. Hasil Pengujian Penggunaan Jenis Android

\section{Kasus dan Hasil Uji (Data Benar)}

\begin{tabular}{|c|c|c|c|}
\hline Data & Skenario & $\begin{array}{l}\text { Hasil yang } \\
\text { diharapkan }\end{array}$ & Kesimpulan \\
\hline $\begin{array}{c}\text { Android } \\
5\end{array}$ & $\begin{array}{l}\text { Sistem operasi dapat di instal } \\
\text { aplikasi yang dibangun dan } \\
\text { menjalankannya. }\end{array}$ & $\begin{array}{l}\text { Dapat menjalankan } \\
\text { fungsi aplikasi } \\
\text { yang dibuat }\end{array}$ & $\begin{array}{c}{[\sqrt{ }] \text { Berhasil }} \\
\text { [-] Tidak berhasil }\end{array}$ \\
\hline $\begin{array}{c}\text { Android } \\
6\end{array}$ & $\begin{array}{l}\text { Sistem operasi dapat di instal } \\
\text { aplikasi yang dibangun dan } \\
\text { menjalankannya. }\end{array}$ & $\begin{array}{l}\text { Dapat menjalankan } \\
\text { fungsi apliakasi } \\
\text { yang dibuat. }\end{array}$ & $\begin{array}{c}{[\sqrt{ }] \text { Berhasil }} \\
\text { [-] Tidak berhasil }\end{array}$ \\
\hline $\begin{array}{c}\text { Android } \\
7\end{array}$ & $\begin{array}{l}\text { Sistem operasi dapat di instal } \\
\text { aplikasi yang dibangun dan } \\
\text { menjalankannya. }\end{array}$ & $\begin{array}{l}\text { Dapat menjalankan } \\
\text { fungsi aplikasi } \\
\text { yang dibuat }\end{array}$ & $\begin{array}{c}{[\sqrt{ }] \text { Berhasil }} \\
\text { [-] Tidak berhasil }\end{array}$ \\
\hline
\end{tabular}


Pada Tabel 2 menunjukan bahwa versi android yang bisa digunakan adalah versi android 5 (Lollipop).

\section{Pembahasan}

Sebelum melakukan implementasi sistem aplikasi touring, peneliti melakukan pengamatan diberbagai media online seperti jurnal maupun website yang berkaitan dengan aplikasi touring ini. Pada penelitian yang dilakukan oleh (Rahardi et al., 2016) hanya sebatas perancangan sehingga belum diketahui kelemahan dan kelebihan dari perancagan tersebut. Kemudian pada website-website yang membahas terkait dengan aplikasi touring seperti (A. Kurniawan, 2017) dan (Wahanaritelindo, 2018) membahas beberapa aplikasi seperti Castrol Power Biking, WeRide, Rbiker. Aplikasi-aplikasi tersebut digunakan hanya untuk touring perorang tidak perkelompok.

Selain melakukan pengamatan pada media online, peneliti juga melakukan observasi dan wawancara terhadap salah satu komunitas motor yang ada di Pekanbaru, yaitu Komunitas HOBIKU. Wawancara menanyakan apa saja yang menjadi kendala saat melakukan touring. Dari wawancara tersebut peneliti mencoba memberikan solusi terkait permaslahan yang dialami oleh para bikers dilapangan.

Hasil wawancara dan observasi yang dilakukan, peneliti membangun sistem aplikasi touring. Pembuatan aplikasi ini dimulai dari perancangan perangkat lunak menggunakan UML, sepeti Use Case Diagram dan Activity Diagram. Kemudian melakukan perancangan desain interface untuk memudahkan pembuatan atau coding pada aplikasi. Setelah dilakukan perancangan sistem tersebut langkah selanjutnya membuat aplikasi touring berdasarkan rancangan sistem aplikasi.

Proses pembuatan dari aplikasi menggunakan tools Android Studio, Sublime Text 3, dan Xampp agar mudah untuk diterapkan pada smartphone android. Aplikasi juga menggunakan fitur OTP agar pengguna sistem ini merasa aman dari gangguan dari luar seperti cracker. Fitur chatting dan notifikasi merupakan pembeda dari aplikasi-aplikasi yang ada pada play store. Berdasarkan tujuan dari penelitian ini, bahwa aplikasi ini ditujukan bagi para komunitas yang akan melakukan touring. Oleh sebab itu penelitian ini melakukan uji coba terhadap salah satu komunitas motor, yaitu komunitas HOBIKU Pekanbaru. Sebelum melakukan uji coba para bikers terlebih dahulu menginstal APK ke smartphone masingmasing. Para bikers yang telah mengistal, kemudian melakukan touring di Kota Pekabaru. Uji coba yang dilakukan adalah mengecek fitur-fitur yang disediakan oleh aplikasi ini. Hasil dari pengecekkan tersebut bisa dilihat pada Tabel 1 dan Tabel 2 pada subbab Hasil.

\section{SIMPULAN}

Penerapan aplikasi touring ini berdasarkan dari wawancara dan observasi yang dilakukan terhadap salah satu komunitas motor yaitu komunitas HOBIKU Pekanbaru. Hasil uji coba yang dilakukan menunjukan bahwa aplikasi ini dapat membantu para bikers khususnya yang melakukan touring secara bersama-sama. Fitur terpenting pada aplikasi ini adalah notifikasi yang dapat memberi tahu jika ada anggota touring ada yang tertinggal. Kelamahan aplikasi ini adalah hanya bisa digunakan pada smartphone yang sistem operasinya Android saja. Untuk itu perlu adanya pengembangan dari aplikasi ini agar bisa dijalankan di sistem operasi lain seperti IOS dan Windows Phone.

\section{REFERENSI}

Alfeno, S., \& Devi, R. E. C. (2017). Implementasi Global Positioning System ( GPS ) dan Location Based Service ( LSB ) pada Sistem Informasi Kereta Api untuk Wilayah Jabodetabek. Sisfotek Global, 7(2), 27-33.

APJII. (2019). Penetrasi \& Profil Perilaku Pengguna Internet Indonesia. Apjii. Diambil dari 
www.apjii.or.id

Canalys. (2019). Samsung leads in Indonesian smartphones as market surges ahead to close 2018 up 17 . $1 \%$. Diambil dari https://www.canalys.com/freereport/latest-freereport?id=15192

Gama, A. W. S., \& Gama, G. (2015). Komunitas Merek Sebagai Sarana Efektif Word of Mouth. Jurnal Bakti Saraswati, 4(1), 1-7.

Hafsah, Rustamadji, H. C., \& Sriyono, A. S. (2012). Aplikasi Pencarian Android Package (Apk) Berbasis Web dan Mobile Web dengan Api. Telematika, 9(1), 51-56.

Khaerul, Julianto, \& Salmah. (2017). Studi Kualitatif Geng Motor Anarkis Di Makassar. Pena : Jurnal Penelitian Dan Penalaran, 3(1), 481-490.

Kurniawan, A. (2017). Castrol Power Biking, Aplikasi Buat Bikers Pecinta Touring. Diambil Dari https://zonabikers.com/castrol-power-biking-aplikasi-buat-bikers-pecinta-touring/

Kurniawan, T. A. (2018). Pemodelan Use Case (UML): Evaluasi Terhadap beberapa Kesalahan dalam Praktik. Jurnal Teknologi Informasi Dan Ilmu Komputer, 5(1), 77-86.

Mustaqbal, M. S., Firdaus, R. F., \& Rahmadi, H. (2015). Pengujian Aplikasi Menggunakan Black Box Testing Boundary Value Analysis (Studi Kasus : Aplikasi Prediksi Kelulusan SNMPTN). Jurnal Ilmiah Teknologi Informasi Terapan, I(3), 31-36.

Naufal, M., \& Purwanto. (2018). Implementasi Keamanan Login dengan Metode One Time Password ( OTP ) Menggunakan Fungsi Hash Algoritma Sha-512. SKANIKA, 1(1), 335339.

Nurbanaat, H., \& Desiningrum, D. R. (2018). Gaya Hidup Anggota Komunitas dan Klub Motor Kota Semarang Pada Usia Dewasa Awal. Empati, 7(1), 9-15.

Rahardi, M., Nugroho, L. E., \& Ferdiana, R. (2016). Perancangan Aplikasi Pendukung Touring Berbasis Contextual Awareness. Seminar Nasional Teknologi Informasi Dan Multimedia STMIK AMIKOM Yogyakarta, 6-7.

Suendri. (2018). Implementasi Diagram UML (Unified Modelling Language) Pada Perancangan Sistem Informasi Remunerasi Dosen Dengan Database Oracle (Studi Kasus : UIN Sumatera Utara Medan). Jurnal Ilmu Komputer Dan Informatika, 3(1), 19.

Sunarsa, A. (2018). Attorney Role In Fighting Crimes Of Motorcycle Gang In Cirebon. Jurnal Daulat Hukum, 1(2), 453-460.

Tristianto, C. (2018). Penggunaan Metode Waterfall Untuk Pengembangan Sistem Monitoring Dan Evaluasi Pembangunan Pedesaan. Jurnal Teknologi Informasi ESIT, $X I I(01), 41-56$.

Wahanahonda. (2018). Perhatikan 7 Hal Ini Saat Berencana Touring Jarak Jauh. Diambil dari https://www.wahanahonda.com/news/perhatikan-7-hal-ini-saat-berencana-touring-jarakjauh

Wahanaritelindo. (2018). Perlengkapan untuk Touring: Aplikasi Penting yang Wajib Kamu Pakai Saat Touring. Diambil dari https://www.wahanaritelindo.com/artikel/perlengkapan-untuk-touring-aplikasi-pentingyang-wajib-kamu-pakai-saat-touring 